\title{
INVESTIGATION OF THE MECHANICAL PERFORMANCE OF FIBER-MODIFIED CERAMIC COMPOSITES USING FINITE ELEMENT METHOD
}

\author{
Majid AHMADI, Seyed Hadi SEYEDIN, Seyed Vahid SEYEDIN
}

\begin{abstract}
Ceramic materials are widely used in impact safekeeping systems. Ceramic is a heterogeneous material; its characteristics depend considerably both on specifications of its ingredients and the material structure completely. The finite element method (FEM) can be a useful tool for strength computation of these materials. In this paper, the mechanical properties of the ceramic composites are investigated, and the mechanical performance modeling of fiber-fortified ceramic matrix composites (CMC) is expressed by the instance of aluminum oxide fibers in a matrix composite based on alumina. The starting point of the modeling is an infrastructure (primary cell) that contains a micromechanical size, the statistical analysis characteristics of the matrix, fiber-matrix interface, fiber, and their reciprocal influences. The numeral assessment of the model is done using the FEM. The numerical results of composite elastic modulus were computed based on the amount of the added fibers and the porosity was evaluated for empirical data of samples with a similar composition. Various scanning electron microscope (SEM) images were used for each sample to specify the porosity. Also, the unit cell method presumed that the porous ceramic substance is manufactured from an array of fundamental units, each with the same composition, material characteristic, and cell geometry. The results showed that when the material consists of different pores and fibers, the amount of Young's modulus reduces with the increment of porosity. The linear correlation model of elasticity versus porosity value from experimental data was derived by MATLAB curve fitting. The experimental data from the mechanical test and numerical values were in good agreement.
\end{abstract}

Keywords: ceramic composite; elasticity; fiber; Finite Element Method (FEM); mechanical performance; thermal stress

\section{INTRODUCTION}

Engineering materials are divided into three technical sections; ceramics, metals, and polymers. Composite is a mixture of various materials from one or more of these parts. One of the phases is often harder, discontinuous, and stronger named as the reinforcement. The less rigid and weaker phase is continuous termed as the matrix. The combination results in different premier properties are not displayed by unique materials. The main advantageous property of composites is mechanical efficiency. Composites contain reinforcement (particles, fibers, flakes, and fillers) embedded in a matrix (metals, polymers, or ceramics). The matrix retains the reinforcement to form the desirable shape while improves all mechanical properties. The important advantageous parameters of fiber-reinforced composites are specific modulus and strength, respectively [1].

Ceramic pieces are broadly used in strike safekeeping systems; the finite element method (FEM) is generally used for strength calculation. As ceramic is a heterogeneous material, its properties depend extremely both on characteristics of the material structure and on its components entirely [2]. Aluminum silicate is used in metallurgical, pottery, glass, and ceramic industries for its resistance or durability. These materials contain refractory soils or clay content. The layered clay stone increases refractories resistance in high-temperature compositions that have a large granule or particle size distribution (PSD) with high porosity and heterogeneous microstructure. Fibermodified composites use has been extended in the world due to ductility, durability, high strength, stiffness, and impact resistance. The major objective of the fiber addition is to enhance the mechanical characteristics, strength in particular [3].
Ceramic matrix composites (CMCs) can be substituted rather than other materials in various applications in which the higher expenses are offset by an increment in performance. They are prone to catastrophic failure due to the lack of stiffness. To benefit from CMCs and minimize problems like a partial failure, modeling and computational software such as finite element analysis (FEA) are fundamental for investigating stuff efficiency nondestructively at the operating conditions and temperatures. FEA is able to define mechanical characteristics, such as inter-laminar shear properties and shear forces, crack deflection, and congested damage failure [4, 5]. A new concept was developed by Tranquart et al. to model complex materials such as CMCs on the Yarn's scale for identifying bending moment diagrams and qualitative data for life cycle anticipation, as well as material design and structure optimization. A novel general finite elements approach (GFEA) such as the novel numerical modeling approach of the CMC yarn, as a suitable modeling scale, has been offered recently. This model depends on a pattern-based explanation of the micro-scale put into a GFEM-like framework. A multiscale and multi-physics macroscopic structure (model) of both the engineering or mechanical action or behavior and the age of self-treatment CMC structures was offered by Genetetal and accredited on the stuff level. The mechanical model considers the fracture or crack networks, as well as its relation with fiber-matrix interrupting through fracture and inelastic stresses or strains. All the simulations have been accomplished through the conventional software package in mechanical engineering such as ABAQUS/Standard FEA [6, 7].

Composites are superior to all other known structural materials in distinct hardness fatigue strength, resistance, high-temperature durability, and other properties. The expected combination of properties can be fitted in advance 
and realized in making a specific material. Many modern technologies need materials, such as metals, ceramics, metal alloys, and polymeric materials with unique combinations of properties that cannot be carried out. The required composite materials for underwater, aerospace, and transportation applications have unique properties. Most of the composites typically have one construction in common, a binder or matrix mixed with a fortified material. A composite is a material developed from two or more distinct phases, matrix and dispersed. If the fibers are directionally oriented and continuous, the material is called an advanced composite. The composite material properties depend on the stiffness of bonds and the physical-mechanical features of their components. A specific advantage of composites is the capability of their components to be utilized fully. Such materials may take specified valuable properties that are not found in the components. To obtain the optimal characteristic in composites, their components are selected to have strongly various but perfect properties. The basis or matrix of composites may consist of metals or alloys (metallic composites), carbon, polymers, and ceramics (non-metallic composites) [8]. Technologically, the most substantial composites are generally those in which the dispersed phase is in the form of a fiber. Indeed, the powerful fibers embedded in a softer matrix produce products with great strength-to-weight proportions. The matrix materials transmit the load to the fibers that absorb the stress.

Also, the linear behavior of ordinary composites and its frame and structure can be described analytically by Classical Laminate Theory (CLT). By investigating elastic mechanical characteristics (Young's moduli parameter, shear modulus of rigidity, and Poisson's ratios), as well as influence of moisture and thermal impact, CLT can effectively compute the stress-strain relations in composite become laminated up to fracture initiation. Through thickness, both the vertical and shear forces are ignored in CLT, thus supposing composite plates to be extremely wide and long that causes neglecting edge effects. Finite element modeling (FEM) dominates these issues and can perform the stress investigation of structures more carefully. Computational or numerical simulation results are being generally used in the design, production, and investigation of several composites and structures. The important parameter in increment of industrial competitiveness is saving or reducing the design age. The capability to finish designs by a proper software on the computer effectively reduces the reliance on long-time methods and costly physical experiments. Composites can be nearly optimized for suitable and special uses. Most commercial FE software possess user-friendly composite mathematical modeling capabilities, which can accurately obtain elastic action through anisotropic or orthotropic constructional modeling. Unlike CLT, FE models allow accurate and regular stress analyses through the accomplishment of an appropriate computerized sample model, leading to the anticipation of stress concentrations [9].

The arrangement or orientation of the fibers, the fiber density, and their distribution all have a significant influence on the resistance and other performances of fiber-modified composites. With regards to direction, two extremes are possible: (1) a parallel arrangement of the fiber longitudinal axis in a single direction; and (2) an accidental adjustment. Mechanical reactions of this unique composite depend on multiple parameters, such as strain-stress behaviors of the matrix phases, fiber, the phase volume fractions, and the direction a load or the stress is enforced to it [10]. In recent years, ceramic material has become increasingly substantial, especially for unique uses that need great strength. Ceramics show superior behavior at high temperatures in general. The difficulty of using ceramics is their fragile harm behavior. A single deficiency or defect can cause fragile damage in the whole structure [11].

Fiber-reinforced or -modified composites have great mechanical performance, such as high unique strength and hardness. Particularly, laminated composite structures have widely been used, where the in-plane properties are substantial [12].

In past decades, the finite element method as an efficient tool has become a broadly accepted computational technique not only in computational mechanics but also in certain engineering majors. The approach has been extended to solve easy linear equations in mechanics of solid bodies along with severe non-linear problems in almost all fields of applied physics or mathematics; and more recently, in many other branches of general science.

Some packages that can be used are FLUENT, ABAQUS, ADINA, ANSYS, NASTRAN, and LUSAS. Finite element method gives a proximate distribution of the needed size in the considered field that is not possible to be specified analytically. A proximate solution is derived by dividing the total area (bodies) to the minor elements. Then, the related physical rules are applied to each element and total elements of the set of solutions to solve the existing problems [13]. One of the novel numerical simulation methods is finite element analysis (FEA) that can evaluate the fracture probability caused by the characteristics and performance of flaw distribution. It is considered an effective tool to facilitate and increase the use of ceramics in components and members; the FEA can also forecast the distribution of ceramic rigidity. Specifically, the needed data on the microstructure distribution (i.e., relative density, porosity, and grain size) are used as the input parameters [14]. Also, the finite element method is done to model the piezo-laminated plate panel as an appropriate composite structure and show the static and dynamic analysis of structural vibrations subjected to an external force. The piezo-laminated structure modeling is based on the assumptions of first-order shear deformation theory (FSDT) [15]. In general, the purpose of the numerical model is to investigate the effect of substantial parameters on the behavior of the fiber composite. This grid frame or substructure (elementary cell) takes fiber, the fiber-matrix interface, the single components matrix, and their particular harm behavior into an account. It is selected in such a way that a macrostructure property for the complete structure can be made by a proper number of substructures. The model has been performed in a finite element method code to research the effect of separate component factors on the behavior of the total. 
In a finite element method modeling, several analyses can be done; for instance, dynamic and static analysis, which later could be modeled and involved forced vibrations. In general, a static linear elastic analysis is the easiest and default one but with limited use due to its closed scope [16]. Modeling of the accidental fiber distribution of a fiberresistant composite via simulation software is of high importance to investigate the approaching failure behavior of the material on the limitation of micro-scale. Fiber-reinforced composites are typically recognized as ordinal materials with three structural levels: macro-scale, mesoscale, and microscale. The micro-scale defines the adjustment of composite fibers in the fiber bundle. The mesoscale typically relates to the fabric/lamina shape or geometry, and the macro-scale composite refers to engineering the structural action of the stuff. In a multi-scale modeling and simulation of composite stuff, micro-scale concepts (including both numericalanalysis and mathematical methods) are usually applied to anticipate the effective rigidity and strength performance of axial symmetry of a composite material or transversely isotropic fundamental properties of composites, which are used as theoretical tools for technical structure design [17, 18]. Recently, a finite element analysis (FEA) modeling has been performed for the long fiber- modified ceramic matrix woven composites (LFMCWCs) sample. For instance, this method has been validated to investigate the grinding process of a $2.5 \mathrm{D}$ woven quartz such as fiber-reinforced silicon dioxide ceramic matrix $\left(\mathrm{SiO}_{2} / \mathrm{SiO}_{2}\right)$ composite. Concerning the grinding tests, their results were directly confirmed for the precision of the FEA method [19].

The strength of these studies is their uniqueness, using various materials and composites, as well as FEM use as a useful tool to analyze and predict the mechanical performance of composites, which is a cost-effective and time-saving approach. However, the past research weaknesses are testing only a few limited materials and some simulations without comparing with experimental data, in particular, microstructure SEM images that are very vital for investigating mechanical performance.

In the present research, only one composite has been modeled with a total detailed account of its physical morphology along with its thermo-physical performances. The composite morphology at micro-scale has been made as close to reality as possible with measurements from SEM micrographs for the geometric details, such as the fiber radius and length. A commercial FE code of ABAQUS has been applied to create the computational model. The real microstructure with fiber distribution has been specified via an SEM image, for example. The science of image analysis has then been done on the main image to determine the fibers based on various color threshold modules, histograms and algorithms. From this image, the data such as the distribution of distances between neighboring fibers and the fiber radius extracted based on image pixels in a black and white image via MATLAB image processing toolbox. The obtained statistical parameters were utilized and employed mesh grids to generate a finite element analysis that was used to anticipate the effective mechanical property and compare it with the experimental data, such as volume fraction, porosity, and elasticity. This study focuses on the mechanical performance of ceramic composites as well as the comparison of experimental data and simulation results.

\subsection{Methodology}

The present study deals with technical performances of the elastic theory originated from FEA of the total representative volume elements in fiber-modified composites. The fibers are put orderly in the square array that is known as the uni-directional composite. An example of a uni-directional fiber composite is shown in Fig. 1.

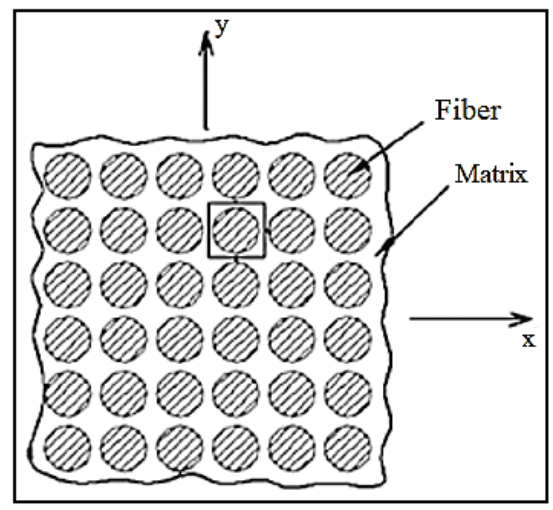

Figure 1 The schematic image of the unit cells.

It is supposed that the fiber and matrix material is usually linearly elastic. Typically, a unit cell is employed for the analysis. The measure of the fiber volume in proportion to the whole volume of the composite is served from the crosssectional areas of the fiber associated with the total crosssectional area of each unit cell. This fraction of composite is considered as a substantial parameter in a composite that is named the fiber volume fraction (VF).

\section{EXPERIMENTAL METHOD}

Some samples were made using the layered claystone, clay, and bauxite in the amounts defined by the Jahad Daneshgahi Corporation according to scientific principles $[21,24]$. Samples with the addition of $1 \%$ wt. content of low alumina-based fibers (with the aspect ratio of $1 / d \approx 17$ ), were added to the composition in order to evaluate the results of numerical modeling to the empirical data. The material was blended in the ball mill with water to enable better distribution of components, proper fibers in particular. The obtained composition was dried within 24 hours at $100{ }^{\circ} \mathrm{C}$ and then pressed between pressures of $35000 \mathrm{kPa}$ to 55000 $\mathrm{kPa}$ to create two various porosities. Other samples were thermally operated at about $1200^{\circ} \mathrm{C}$ and then were tested via the compaction and the Brazilian tests [20] to get the values of elasticity modulus $(E)$ and strength $(F)$. The test was done via the modern-hydraulic testing system (Instron testing system, Model 1362) with a load cell of $5000 \mathrm{~N}$ and $100 \mathrm{kN}$ through a data logger. The calculated values of modulus were served to evaluate the numerically obtained values [21]. The whole samples were experimented using the scanning 
electron microscope (SEM), and captured images were employed to determine their porosity [22].

Porosity values were measured based on the various threshold level of darkness of the obtained images via the image processing method. Different SEM images of each sample were used to determine the porosity of various samples. This method is appropriate since the pore, absorbs more light, and it takes place as part of the image darker than of the solid material. Given the porosity of the material and the proper method for determining the number and share of pores, given in Fig. 2, the microstructure images were captured using an SEM system, (the Zeiss DSM-960A model, operated at the range of $21 \mathrm{kV}$ ).

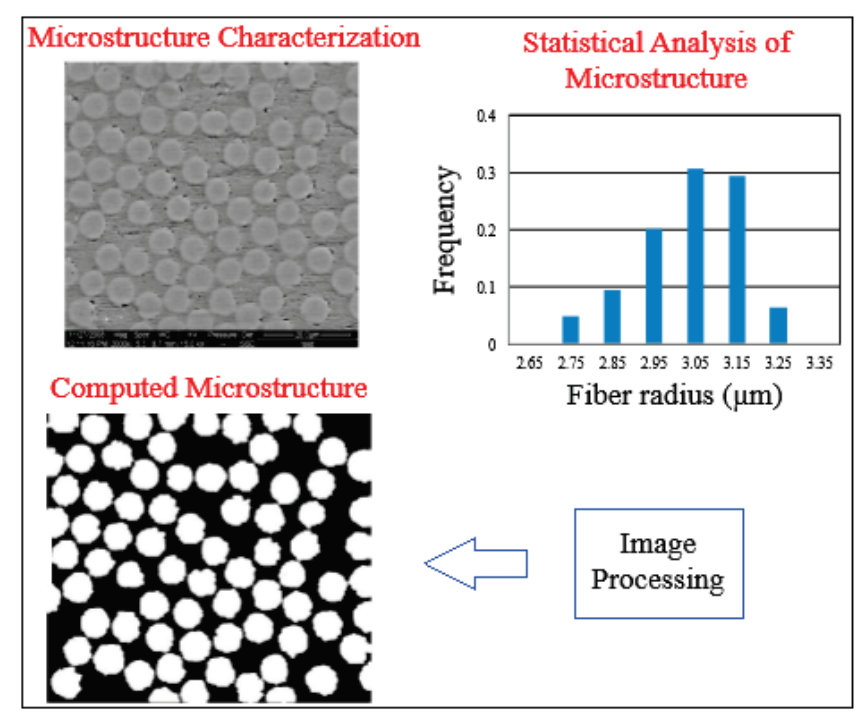

Figure 2 The digital image for micromechanical modeling of an accidental descriptive volume element in a composite. The SEM image is taken from [22].

\subsection{The Explanation of the Finite Element Analysis}

The unit cell approach supposes that the porous ceramic has been made of an array of fundamental elements or units, each with the same composition, cell shape or geometry, and material characteristics. A plate cubic cell is investigated as a descriptive volume element to model and simulate the real microstructures of porous ceramics. This simulation supposes that: a) the ceramic matrix is investigated as being isotropic; b) the elastic performance of the ceramic composite is linear $[6,25]$.

Total 3D finite element (FE) simulations were generated using ABAQUS 2018, FE software package. Total material data was used for FE simulation and the matrix:

For fibers: the first Young's modulus $E_{1}=145000 \mathrm{MPa}$ and Poisson's ratio of $v_{1}=0.25$; the second Young's modulus $E_{2}=10000 \mathrm{MPa}$ with Poisson's ratio of $v_{2}=0.20$.

\section{RESULTS AND DISCUSSION}

The mesh geometry was generated by computational cell elements derived from image processing of the material SEM, and certain calculations were done based on the combination of the material. Moreover, the volume fraction of the fibers was chosen while making the material and fixed on $1 \%$ volume. The fiber dimensions were obtained by evaluating short fibers via the image processing program. According to Fig. 1, the average fiber length was $0.1344 \mathrm{~mm}$, and the average fiber radius was $0.003 \mathrm{~mm}$. Thus, the formula for calculating the volume of the single cylindrical fiber was computed as follows:

$$
V_{\mathrm{f}}=\pi r^{2} l=\pi(0.003)^{2} \times 0.1344=3.8 \times 10^{-6} \mathrm{~mm}^{3}
$$

The material volume was computed from total fiber constituents using the simple equation based on the cell volume of $0.0000038 \mathrm{~mm}^{3}$ and edge length of $0.068 \mathrm{~mm}$. Since the fiber length is $0.1345 \mathrm{~mm}$ and also the unit cell can be big enough, the fiber can fit in each cell. The presumption that eight fibers belong to one elementary cell provides a cube with the dimensions of $0.14 \mathrm{~mm} \times 0.14 \mathrm{~mm}$, and the depth of $0.14 \mathrm{~mm}$; also, the fiber radius is $r=0.003425 \mathrm{~mm}$, and the length is $l=0.137388 \mathrm{~mm}$. They are the same for entire fiber volume fractions. The calculated volume fractions of elementary cells for various fibers have an error range of $0.04-0.1$ in proportion to various fiber volumes in ceramic.

All fibers were randomly put into a matrix, which included 4 and 8 fibers. The schematic representation of fiber has been shown in Fig. 3.

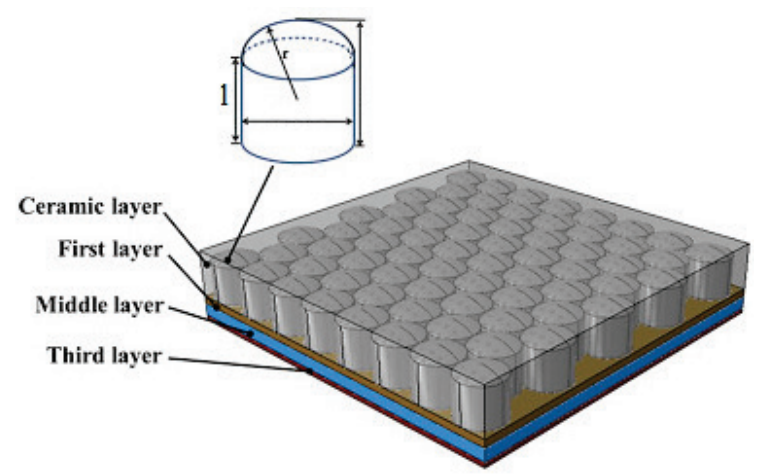

Figure 3 The schematic diagram of the designed ceramic composite system.

To investigate the effect of porosity on mechanical characteristics, the elementary cell was produced with fibers without pores and cells that were put into the pores.

The schematic representation of the mesh grid according to the unit cell has been shown in Fig. 4.

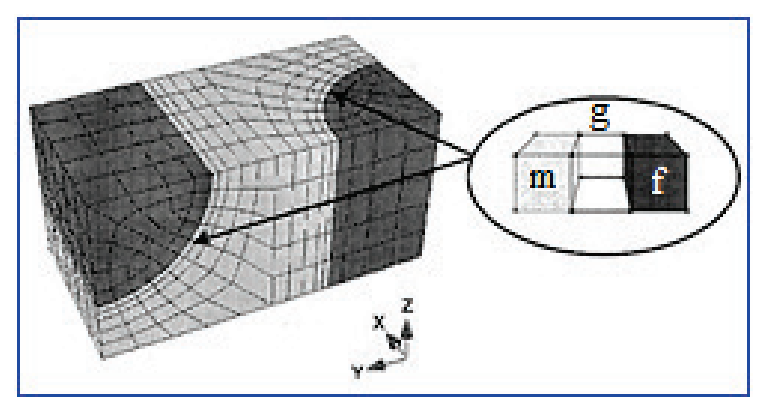

Figure 4 Schematic representation of the finite element unit cell 
Fig. 5 shows the unit cell: a) the fibers with pores (porous fibers); and $b$ ) the fibers without pores. It can be realized that the existing contact between matrix and fibers is the surface to surface contact type with a friction factor of 0.1 . In the software, it is determined that the surface to surface contact is as of the finite sliding and the friction formulation as of the penalty.

\subsection{Calculation of Mechanical Properties by Analytical Solution}

The mechanical performance of the lamina is computed using the following equations of Elasticity Theory, as well as Halphin-Tsai's formulae; Linear Young's Modulus equation in the fiber for each direction is as follows:

$$
E=\frac{\sigma}{\varepsilon}
$$

$\sigma$ is the stress, and $\varepsilon$ is the strain in each direction $(x, y$ or $z)$.

$$
v_{12}=-\frac{\varepsilon_{2}}{\varepsilon_{1}}
$$

$\varepsilon_{1}, \varepsilon_{2}$ are the strains in various directions $(x, y, z)$.

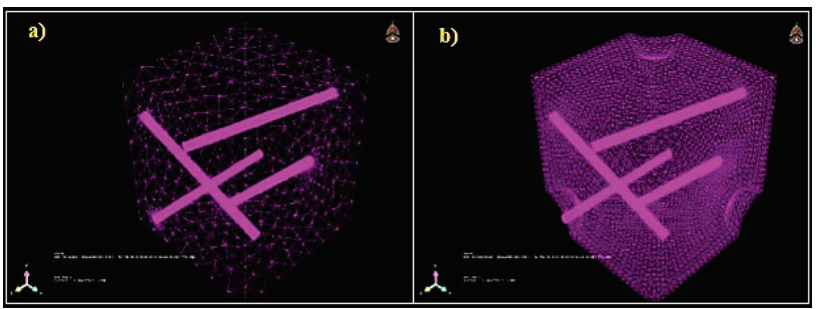

Figure 5 Elementary cells: a) with fibers and pores; and b) with fibers without pores.

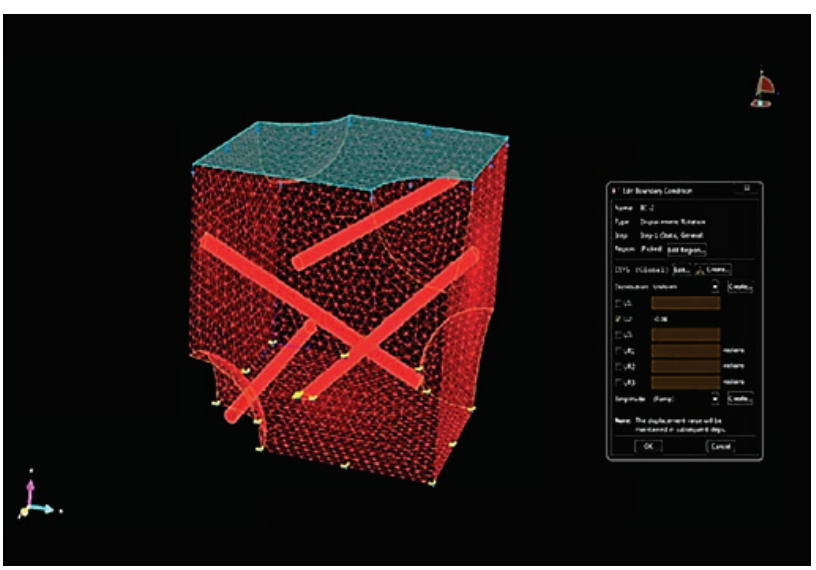

Figure 6 The impact of the load on the elementary cell.

Experimental data for pure $\mathrm{Al}_{2} \mathrm{O}_{3}$ used to simulate the alumina ceramic are summarized in Tab. 1. It should be noted that the physical properties of the material (Density $\rho$, Specific heat $C_{\mathrm{p}}$, Thermal conductivity $\lambda$, Young's modulus $E$, Poisson's ratio $v$, and thermal expansion factor $\alpha$ ) have been reported in Tab. 1 according to the density (without pores) from the Tab. 1.

Table 1 Physical properties of alumina $\left(\mathrm{Al}_{2} \mathrm{O}_{3}\right)$.
\begin{tabular}{|c|c|c|c|c|c|}
\hline $\begin{array}{c}\rho \\
\left(\mathrm{g} / \mathrm{cm}^{3}\right)\end{array}$ & $\begin{array}{c}C \mathrm{p} \\
(\mathrm{J} / \mathrm{g} \cdot \mathrm{K})\end{array}$ & $\begin{array}{c}A \\
(\mathrm{~W} / \mathrm{m} \cdot \mathrm{K})\end{array}$ & $\begin{array}{c}E \\
(\mathrm{GPa})\end{array}$ & $v$ & $\begin{array}{c}A \\
(1 / \mathrm{K}\end{array}$ \\
\hline 3.989 & 0.78 & 29 & 390 & 0.22 & 9.1 \\
\hline
\end{tabular}

Fig. 6 shows the matrix with 8 fibers. This model of elementary mesh grid cell is originated from the matrix in which it does not have any pores.

\subsection{Comparison of Experimental and Calculated Parameters of Elastic Modulus}

To evaluate the achieved numerical simulation results, the derived data were tested and analyzed via a mechanical experiment. The obtained values of elastic modulus for various combinations are divided into two main parts: one with only pores, and one with fibers and pores simultaneously, which are shown in Fig. 7. The experimental data were also added to the data diagram and fitted with the model extended in this study. When the material consists of pores and fibers, the quantity of Young's modulus reduces with the increment of porosity. The value of Young's modulus in the improved material with fiber has greater amount as compared to the material without fiber including the same porosity. Poisson's ratio, generally, decreased with an increasing fiber volume fraction according to Eq. (4).

$v=v_{\mathrm{f}} V_{\mathrm{f}}+v_{\mathrm{m}} V_{\mathrm{m}}$

In this equation, $v_{\mathrm{f}}$ is Poisson's ratio of fiber, and $v_{\mathrm{m}}$ is Poisson's ratio of a matrix.

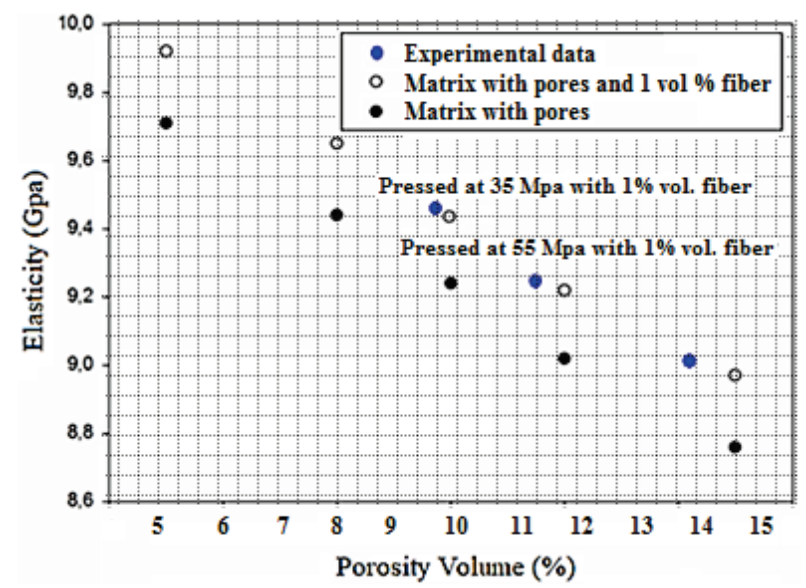

Figure 7 Young's modulus of elasticity versus the porosity volume.

Fig. 8 shows the linear regression model of the elastic modulus obtained by the experimental data.

This linear correlation was calculated by MATLAB software of version $\mathrm{R} 2014 \mathrm{~b}$ as follows:

$E=-0.08871 \varepsilon+10.27$ 


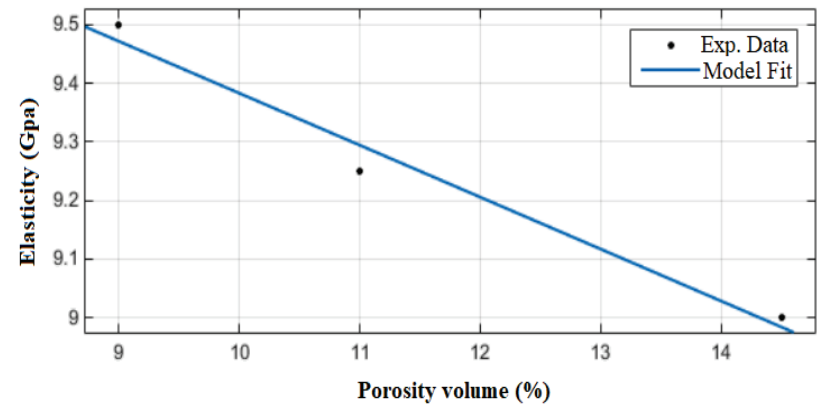

Figure 8 Linear curve fitting model of elasticity versus porosity value (\%).

In this equation, $E$ is elastic modulus $(\mathrm{GPa})$, and $\varepsilon$ is porosity volume (\%). Eq. (5) signifies that with increasing porosity volume, the modulus of elasticity decreases. The experimental data shows good consistency with the linear model. Also, the statistical parameters verify the accuracy of the experimental results. The quality of fitness is presented in Tab. 2.

Table 2 Statistical data calculated by MATLAB software.

\begin{tabular}{|l|c|}
\hline \multicolumn{1}{|c|}{ Statistic parameter } & Calculated value \\
\hline SSE & 0.003024 \\
\hline R-Square & 0.975800 \\
\hline Adjusted R-Square & 0.951600 \\
\hline RMSE & 0.054990 \\
\hline
\end{tabular}

Compared to the experimental values derived from mechanical experiment, it presents good consistency of experimental and calculated values in the model.

Schematic flowchart for preparing samples of each experiment is shown in Fig. 9.

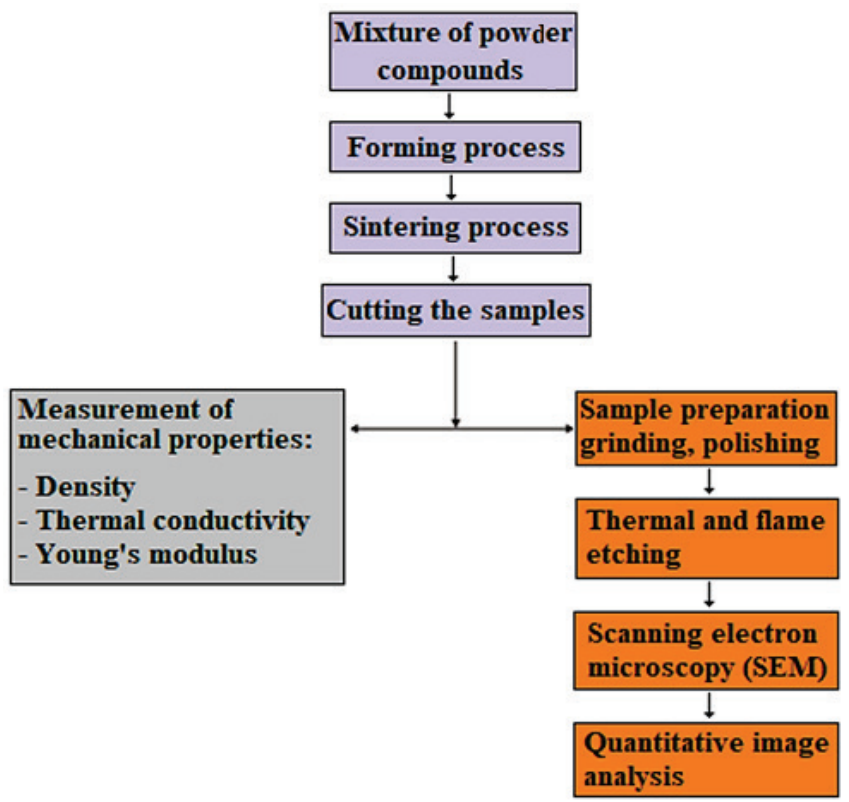

Figure 9 Schematic flowchart describing the experimental procedure of samples.

In the present research, the finite element analysis has been done to anticipate the engineering and mechanical properties of the fibers in the field of a fiber-modified ceramic composite. The simulation results were validated with the results obtained from the experimental data. In addition, it was found that the mechanical properties of a ceramic composite such as $E, \varepsilon, \sigma$, and $v$ are strong functions of volume fraction in the fibers. The results showed that any change in the dimension or volume and porosity of the fibers could influence the mechanical properties of a composite.

\section{CONCLUSION}

The finite element method, as a useful model, is a powerful tool to investigate the different properties of composite materials. The effect of resistance, stiffness, and reinforcement distribution in mechanical properties of composite material is considered by checking the finite element analysis and micromechanics approach.

In this study, the geometry of the mesh was obtained through calculating elements of unit cells, which had been obtained from image processing; it is used for the analysis of the material SEM images, as well as certain calculations based on the material performance. The information obtained from the mechanical analysis test was employed to evaluate the achieved simulation results. The experimental data was also added to the data diagram, and the information fitted the FEM simulation model was extended in this research. The results showed that when the material consists of pores and fibers, the index of Young's modulus reduces with the increment of the porosity. The value of Young's modulus of either enhanced or fortified material, including fibers has greater values compared to the material without fiber with the same porosity. The linear model of the elastic modulus, which was obtained by the experimental data and was compared to empirical values originated from a mechanical test, signifies good consistency with those computed values of the mathematical simulation model.

The numeral model was extended based on the investigation of mechanical behavior, parallel to measured porosity properties, and a linear mathematical model was derived for elasticity modulus with appropriate accuracy by experimental data. The number of entire fibers was prepared in each experiment in the cube related to the combination of the material. The used materials were examined mechanically and by means of simulation results in order to get the key values of elastic modulus, physical and engineering properties, as well as the structure, which was tested by the image processing analysis of the SEM images. The number and size of the pores and porosity were the basis for calculating the proper elementary cube for computer simulation. Finally, the experimental and simulation data were in good agreement.

\section{Acknowledgments}

This research has been guided and supported by a professional mechanical engineer, Seyed Hassan Alhoseini.

\section{REFERENCES}

[1] James Paul, K. \& Sd. Abdul Kalam. (2016). Mechanical Properties of Okra Fiber Reinforced Composites Using Fem, 
International Journal of Advanced Research in Mechanical Engineering \& Technology (IJARMET), 2(2).

[2] Shchurova, E. I. (2016). Modeling of the Ceramics Structure for the Finite Element Analysis. Procedia Engineering, 150, 179-184. https://doi.org/10.1016/j.proeng.2016.06.744

[3] Sadik, C., El Amrani, I. E., \& Albizane, A. (2014). Recent advances in silica-alumina refractory: A review. Journal of Asian Ceramic Societies, 2(2), 83-96. https://doi.org/10.1016/j.jascer.2014.07.006

[4] Choi, A. H., Heness, G., \& Ben-Nissan, B. (2014). Using finite element analysis (FEA) to understand the mechanical properties of ceramic matrix composites. In Advances in Ceramic Matrix Composites, 286-311. https://doi.org/10.1533/9780857098825.2.286

[5] Choi, A. H., Heness, G., \& Ben-Nissan, B. (2018). Using finite element analysis (FEA) to understand the mechanical properties of ceramic matrix composites. In Advances in Ceramic Matrix Composites (pp. 375-400). https://doi.org/10.1016/B978-0-08-102166-8.00016-5

[6] Boccaccini, A. R. \& Fan, Z. (1997). A new approach for the Young's modulus-porosity correlation of ceramic materials. Ceramics International, 23(3), 239-245. https://doi.org/10.1016/S0272-8842(96)00033-8

[7] Farooqi, J. K. \& Sheikh, M. A. (2006). Finite element modelling of thermal transport in ceramic matrix composites, Computational Materials Science 37, 361-373. https://doi.org/10.1016/j.commatsci.2005.11.001

[8] Callister, W. D. \& Rethwisch, D. G. (2011). Materials science and engineering (Vol. 5, pp. 344-348). NY: John Wiley \& Sons.

[9] Reiner, J. \& Vaziri, R. (2018). Structural Analysis of Composites with Finite Element Codes: An Overview of Commonly Used Computational Methods, Comprehensive Composite Materials II, Vol. 8. https://doi.org/10.1016/B978-0-12-803581-8.10050-5

[10] Ismar, H., Schröter, F., \& Streicher, F. (2000). Modeling and numerical simulation of the mechanical behavior of woven $\mathrm{SiC} / \mathrm{SiC}$ regarding a three-dimensional unit cell. Computational Materials Science, 19(1-4), 320-328. https://doi.org/10.1016/S0927-0256(00)00170-1

[11] Kakani, S. L. \& Kakani, A. (2010). Material Science, New Age International Pvt Ltd Publishers.

[12] Tao Zeng, Lin-zhi Wu, \& Li-cheng Guo. (2004). Mechanical analysis of 3D braided composites: a finite element model. Composite Structures, 64, 399-404. https://doi.org/10.1016/j.compstruct.2003.09.041

[13] Dimitrijević, M. M., Tomić, N., Međo, B., Jančić-Heinemann, R., Rakin, M., \& Volkov-Husović, T. (2014). Modeling of the mechanical behavior of fiber-reinforced ceramic composites using (FEM). Science of Sintering, 46(3), 385-390. https://doi.org/10.2298/SOS1403385D

[14] Ozaki, S., Aoki, Y., Osada, T., Takeo, K., \& Nakao, W. (2018). Finite element analysis of fracture statistics of ceramics: Effects of grain size and pore size distributions. Journal of the American Ceramic Society, 101(7), 3191-3204. https://doi.org/10.1111/jace.15468

[15] Sharma, A. (2018). The finite element based study on active attenuation of structural vibration using porous ferroelectric ceramics. In AIP Conference Proceedings (Vol. 1975, No. 1, p. 030007). AIP Publishing. https://doi.org/10.1063/1.5042177

[16] Pedro Colmar Gonçalves da Silva Vellasco, Luciano Rodrigues Ornelas de Lima, Luís Alberto Proença Simões da Silva. (2017). Finite Element Modelling, Modelling Steel and Composite Structures, Chapter 3, 209-211. https://doi.org/10.1016/B978-0-12-813526-6.00003-9
[17] Wenzhi Wang, Yonghui Dai, Chao Zhang, Xiaosheng Gao \& Meiying Zhao. (2016). Micromechanical Modeling of FiberReinforced Composites with Statistically Equivalent Random Fiber Distribution. Journal of Materials (MDPI). https://doi.org/10.3390/ma9080624

[18] Samadi, F. \& Missagh Shamshiri, G. S. (2019). Numerical Modeling for Simulation of Contaminant Migration of Leachate in Soil Media. arXiv preprint arXiv:1905.02280.

[19] Yuguo Wang, Haoji Wang, Jinhua Wei, Bin Lin, Jingyu Xu, \& Sheng Fang. (2019). Finite element analysis of grinding process of long fiber reinforced ceramic matrix woven composites: Modeling, experimental verification and material removal mechanism. Ceramics International, 45(13), 592015927. https://doi.org/10.1016/j.ceramint.2019.05.100

[20] Andreev, G. E. (1991). A review of the Brazilian test for rock tensile strength determination. Part I: calculation formula. Mining Science and Technology, 13(3), 445-456. https://doi.org/10.1016/0167-9031(91)91006-4

[21] Dimitrijević, M. M., Veljović, D., Posarac-Marković, M., Jančić-Heinemann, R., Volkov-Husović, T., \& Zrilić, M. (2012). Mechanical properties correlation to processing parameters for advanced alumina-based refractories. Science of Sintering, 44(1), 25-33. https://doi.org/10.2298/SOS1201025D

[22] See http://thermalceramics.com/products/categories/bulk

[23] Yang, Z. (2010). Effect of Interphase on the Prediction of Mechanical Properties for Unidirectional Composites. Ph.D. Thesis, Harbin Institute of Technology, Harbin, China.

[24] Bunshah, R. F. (2001). Handbook of hard coatings, Deposition Technologies, Properties. New York: Noyes Publication.

[25] Dimitrijevic, M., Heinemann, R. J., Husovic, T. V., Posarac, M., \& Majstorovic, J. (2011). Morphological analysis of surface degradation of advanced alumina based refactories subjected to thermal shock. Procedia Engineering, 10, 21532157. https://doi.org/10.1016/j.proeng.2011.04.356

\author{
Authors' contacts: \\ Majid AHMADI \\ Department of Mechanical Engineering, \\ Science and Research Branch, \\ Islamic Azad University (SRBIAU), \\ Daneshgah Blvd, Simon Bulivar Blvd, Hesarak area, Tehran, Iran

\section{Seyed Hadi SEYEDIN} \\ Corresponding author \\ Department of Chemical Engineering, \\ Science and Research Branch, \\ Islamic Azad University (SRBIAU), \\ Daneshgah Blvd, Simon Bulivar Blvd, Hesarak area, Tehran, Iran \\ sh.seyedin@iran.ir
}

\section{Seyed Vahid SEYEDIN}

Department of Software Engineering,

Tehran South Branch, Islamic Azad University,

Deh haghi (Ahang) Ave, Abuzar Blvd, Afsariyeh Highway, Tehran, Iran 